\title{
AS REPRESENTAÇÕES SOCIAIS DO ALEITAMENTO MATERNO PARA
} MÃES DE PREMATUROS EM UNIDADE DE CUIDADO CANGURU

\author{
Marly Javorski ${ }^{1}$ \\ Laise Conceição Caetano \\ Maria Gorete Lucena de Vasconcelos ${ }^{3}$ \\ Adriana Moraes Leite ${ }^{4}$ \\ Carmen Gracinda Silvan Scochi ${ }^{4}$
}

\begin{abstract}
Javorski M, Caetano LC, Vasconcelos MGL, Leite AM, Scochi CGS. As representações sociais do aleitamento materno para mães de prematuros em unidade de cuidado canguru. Rev Latino-am Enfermagem 2004 novembro-dezembro; 12(6):890-8.

Os objetivos do estudo foram identificar as representações sociais sobre aleitamento materno de pré-termo, em unidade de Cuidado Canguru, sob a óptica das mães que estão amamentando, e descrever os conflitos e contradições que eles vivenciam nesse contexto institucional. A pesquisa utiliza-se de uma abordagem qualitativa em que foi empregado 0 primeiro estágio da análise de enunciação à luz da Teoria das Representações Sociais. As representações encontradas são: os bebês saudáveis são alimentados no peito, o leite materno confere a proteção e a preservação da vida de uma criança prematura, o aleitamento materno é o complemento da maternidade e amamentar um bebê prematuro é uma experiência difícil e desgastante. Os conflitos são decorrentes da assimilação de conteúdos e discurso técnico, sucção tardia e representações sobre leite materno.
\end{abstract}

DESCRITORES: aleitamento materno; método mãe canguru; enfermagem neonatal

\section{SOCIAL REPRESENTATIONS ON BREASTFEEDING} ACCORDING TO PRETERM INFANTS' MOTHERS IN KANGAROO CARE

This study aimed to identify the social representations on premature infants' breastfeeding at a Kangaroo Care Unit, from the perspective of mothers who are breastfeeding and describe the conflicts and contradictions they experience in this context. A qualitative approach was adopted, using the first stage of enunciation analysis in the light of Social Representations theory to identify the meanings assigned to breastfeeding. We found the following representations: healthy babies are breastfed, mother's milk provides protection and preserves the premature child's life, breastfeeding is the complement of motherhood and breastfeeding a premature infant is a hard and exhausting experience. The conflicts resulted from the assimilation of technical contents and discourse, late sucking and representations on breastfeeding.

DESCRIPTORS: breastfeeding; kangaroo mother care; neonatal nursing

\section{REPRESENTACIONES SOCIALES DE LA LACTANCIA MATERNA PARA MADRES DE PREMATUROS EN EL CUIDADO CANGURO}

Los objetivos del estudio fueron identificar las representaciones sociales de la lactancia materna al bebe prematuro en la unidad de cuidado canguro bajo la óptica de las madres que están amamantando y describir los conflictos y contradicciones que vivencian en el contexto institucional. Fue adoptada una aproximación cualitativa, empleándose la primera fase del análisis de enunciación a la luz de la teoría de representaciones sociales. Las representaciones encontradas son: Los bebes saludables son alimentados a pecho, la leche materna da protección y preservación de la vida a un niño prematuro, la lactancia materna es el complemento de la maternidad y dar lactancia a un bebe prematuro es una experiencia difícil y desgastante. Los conflictos y contradicciones resultan de la asimilación de contenidos y discurso técnico, succión tardía y representaciones sobre la leche materna.

DESCRIPTORES: lactancia materna; cuidado madre canguro; enfermería neonatal

\footnotetext{
${ }^{1}$ Mestre, Professor Assistente da Universidade Federal de Pernambuco; ${ }^{2}$ Doutorando, Professor Assistente da Universidade Federal de Minas Gerais; ${ }^{3}$ Doutorando, Professor Assistente da Universidade Federal de Pernambuco; ${ }^{4}$ Docentes da Escola de Enfermagem de Ribeirão Preto, da Universidade de São Paulo, Centro Colaborador da OMS para o desenvolvimento da pesquisa em enfermagem, e-mail: cscochi@eerp.usp.br
} 
INTRODUÇÃO

As mães de crianças nascidas pré-termo, que necessitam de cuidados especiais em Unidades de Terapia Intensiva Neonatal e de Cuidado Canguru, vivenciam situações particulares em relação ao aleitamento materno, determinadas, de um lado, pela prematuridade e, de outro, pelos sentimentos de culpa, sofrimento e fracasso frente à situação de fragilidade e risco a que o filho está exposto.

O aleitamento materno em situação de prematuridade tem nos preocupado, pois, no trabalho assistencial, temos convivido com a insegurança, ansiedade e sofrimento das mães, bem como com o constrangimento, dúvidas e, às vezes, com a impotência dos profissionais de saúde diante da alimentação natural do prematuro. Observamos que é comum essas mães desejarem, em princípio, aleitar seus filhos, entretanto elas vivenciam a iminência do fracasso no aleitamento materno face às inúmeras variáveis a que estão expostas, as quais colaboram para diminuir a produção e ejeção do leite. Apesar disso, o comum nessas situações é a utilização de uma abordagem biologizante pelos profissionais de saúde, sem contemplar os aspectos emocionais vivenciados pelas mulheres, traduzida em intervenções essencialmente técnicas e prescritivas.

Por outro lado, estudo mostra que a assistência ao prematuro tem passado por transformações através dos tempos, tendo, como determinantes, o desenvolvimento socioeconômico, político e cultural. Uma assistência fundamentada em normas rígidas de isolamento transformou-se, tendo como objeto de ação os binômios mãe e filho, a família e a comunidade, envolvendo tecnologias cada vez mais complexas e o trabalho de uma equipe multiprofissional; o paradigma biotecnológico foi substituído pelo holismo ${ }^{(1)}$.

Atualmente, centros de neonatologia estão utilizando, na assistência aos prematuros, uma tecnologia conhecida como Método Canguru. Esse método originouse em 1979, em Bogotá, Colômbia, e vem obtendo resultados positivos, sendo recomendado pelo UNICEF, principalmente para os países em desenvolvimento e do terceiro mundo ${ }^{(2)}$. O Ministério da Saúde, por meio da Portaria $n^{\circ}$ 693, de 5 de julho de 2000, recomenda a adoção dessa estratégia com base nos princípios da humanização da assistência e de cidadania ${ }^{(3)}$.

No Método Canguru, o contato íntimo do bebê com o corpo materno ajuda na regulação da temperatura corporal da criança, na promoção do aleitamento materno e na diminuição da incidência de infecção, e propicia o apego entre mãe e filho. As pesquisas apontam maior duração na continuidade do aleitamento materno e maior satisfação e autoconfiança das mães em relação aos filhos prematuros $^{(4-6)}$.

Poucos trabalhos na literatura contemplam as dificuldades maternas para aleitar um prematuro. No geral, centram-se nos aspectos nutritivos e nas vantagens do leite humano para o bebê pré-termo ${ }^{(7-8)}$, bem como analisam a prevalência e duração do aleitamento, além da redução do tempo de hospitalização e do choro ${ }^{(9)}$.

O Cuidado Canguru, por oportunizar o contato pele a pele e a permanência da mãe junto ao filho prematuro, tem sido apontado como facilitador da amamentação materna entre esse segmento populacional. Uma extensa revisão da literatura foi feita sobre o Cuidado Canguru, citando alguns autores que estudaram a relação entre aleitamento materno e esse tipo de assistência. Os estudos apontaram que essas mães amamentavam por mais tempo, após a alta hospitalar ${ }^{(4)}$.

Apesar de os estudos abordarem aspectos relacionados ao fracasso do aleitamento materno, ainda não estão claros os reais motivos que levam ao desmame e nem como as mães vivenciam o aleitamento de um prematuro, embora a assistência por meio do Método Canguru seja considerada uma estratégia positiva no sucesso da amamentação materna desses bebês. Assim, percebemos que há lacunas na produção de conhecimento que contemple as especificidades da prática de amamentar essas crianças.

Os questionamentos e as inquietações decorrentes da reflexão sobre a nossa prática associada à constatação de que pouco tem sido produzido no Brasil, sobre o aleitamento materno da criança prematura, na perspectiva materna, motivaram-nos a realizar o presente estudo na busca de compreender melhor as particularidades e dificuldades por que passam essas mães no processo de amamentar seu filho prematuro no Método Canguru, identificando as representações sociais presentes nessa situação especial. Dessa forma, os objetivos do presente estudo são identificar as representações sociais sobre o aleitamento materno do pré-termo, em Unidade de Cuidado Canguru, sob a óptica das mães que estão amamentando, e descrever os conflitos e contradições que vivenciam nesse contexto situacional. 
Escolhemos a pesquisa qualitativa pelo fato de privilegiar a ação dos sujeitos e apoiar-se na relevância dos aspectos subjetivos da ação social ${ }^{(10)}$. Apreender os significados atribuídos à amamentação por essas mães passa pelo entendimento da subjetividade da ação expressa por meio da linguagem, que foi construída não só por mecanismos cognitivos, mas também por determinações socioculturais e ideológicas.

Para leitura dessa realidade, optamos pela Teoria das Representações Sociais, como base teórica por acreditarmos que esse referencial nos permitirá olhar 0 fenômeno na perspectiva do sujeito que o vivencia.

As representações sociais são definidas como "uma forma de conhecimento, socialmente elaborada e partilhada, tendo uma visão prática e concorrendo para a construção de uma realidade comum a um conjunto social"(11). Assim, as representações sociais constituem uma forma de conhecimento prático que contempla o saber do senso comum, e são uma orientação para a ação que, por sua vez, engloba uma rede de representações que ligam o objeto ao contexto ${ }^{(12)}$.

As representações da amamentação foram acessadas junto a seis mães, após assinatura do termo de consentimento livre e informado, as quais foram identificadas por codinomes. As mães eram procedentes de diferentes extratos sociais, usuárias de serviços públicos de saúde, estavam acompanhando o filho prematuro em Cuidado Canguru e amamentavam no peito, pelo menos uma vez ao dia. As relações no aqui-agora (no momento vivido) foram observadas no processo de interação entre os sujeitos em uma instituição hospitalar filantrópica, detentora do título Hospital Amigo da Criança, de referência terciária para a assistência ao parto e ao recém-nascido, no Estado de Pernambuco, localizada na capital, Recife. O projeto foi aprovado pelo Comitê de Ética em Pesquisa da instituição.

Para a coleta de dados, utilizamos a técnica da entrevista semi-estruturada, gravada, orientada por um instrumento previamente elaborado e um roteiro temático com as seguintes questões: fale de sua vivência/ experiência de amamentar ou aleitar (por meio da ordenha) seu filho prematuro; quais foram as dificuldades e as preocupações mais marcantes para você nesse período em que esteve internada junto com o bebê? Como você lidou com isso? próximo possível da realidade vivenciada pelos sujeitos pesquisados, utilizamos, também, a observação de campo cujos dados acerca do contexto foram registrados em um diário de campo.

Para a análise e interpretação dos dados deste estudo, utilizamos parte da técnica de análise de enunciação proposta por Laurence Bardin ${ }^{(13)}$, ou seja, a primeira etapa proposta, a análise temática. As falas das entrevistadas são apresentadas em itálico e utilizando a seguinte legenda: $\{\ldots$ pausa durante a fala, /.../ recortes de outras falas e ... recortes da mesma fala.

\section{RESULTADOS}

As mães eram procedentes da capital e cidades do interior do estado de Pernambuco, com idade entre 18 e 35 anos, sendo duas casadas e as demais viviam em união consensual. Quanto ao nível de escolaridade, três concluíram o ensino fundamental, e o restante, o $2^{\circ} \mathrm{grau}$ completo. Cinco mães eram primíparas, e apenas uma estava na segunda gestação, com experiência anterior em amamentação.

Após a análise temática das seis entrevistas, identificamos cinco temas: "crescimento e desenvolvimento e amamentação materna", "leite materno e proteção", "maternidade e amamentação", "amamentação e amor materno" e "a prática de amamentar um prematuro".

Tema 1 - Crescimento e desenvolvimento e amamentação materna

Esse significado foi enunciado a partir dos núcleos de sentido expressos pelas entrevistadas: ficar forte, criarse sadio, crescer bem, estar engordando, estar grande, ficar saudável, se desenvolver, recuperar-se mais rápido, ele pode se criar.

As mães entrevistadas representaram o aleitamento materno como importante na promoção do crescimento e desenvolvimento saudável do filho pré-termo:

...quando o seu nenê não tá conseguindo se alimentar, você fica assim \{__ atenciosa, querendo \{__ que ele se alimente direitinho pra que possa vê ele crescer /.../ ele é uma criança mais saudável /.../O significado de ... amamentar acho que ele vai se recuperar mais ainda, vai ser uma criança saudável ... ajudar ele a ser uma criança saudável. (Nane) 
/.../ significa que ele pode se criá ... E eu sempre amamentando ele vai me dar a segurança de que sempre ele vai reagir e crescer bem. /.../ É criar o Júnior sadio. (Mariana)

...ele fica forte, saudável, porque é bom porque desenvolve mais. (Elma)

... se amamentar eu acho que eu tô contribuindo pra que ela cresça. (Verônica)

... Cada vez mais, cada vez mais ele tá engordando, tá crescendo sei lá \{_\} tá desenvolvendo, eu acho que é porque ele mama, né? Porque a criança que mama, geralmente fica mais saudável, mesmo que ela não seja, mas ela passa a ser saudável. (Elis)

A representação criança saudável é aquela que mama no peito foi compartilhada pelas mães, mesmo por aquelas que estavam passando por dificuldades na amamentação.

Essa dimensão do aleitamento materno denota a incorporação do discurso técnico difundido por meio de campanhas veiculadas pela mídia e de práticas assistenciais. Mesmo as mulheres que não desejam amamentar, demonstram conhecer as propriedades do leite materno e sua influência no crescimento e desenvolvimento da criança ${ }^{(14)}$.

Todavia, devido à especificidade do processo de nascimento de um filho pré-termo, a dimensão do crescimento, traduzido nas falas das mães pelo ganho de peso e pelo desejo de sentir os filhos ficarem fortes por meio do seu próprio leite, constitui-se a ênfase do discurso.

O peso da representação do aleitamento materno, enquanto fator de recuperação e crescimento do prematuro, pode gerar conflito e sentimento de culpa, evidenciado na fala de uma mãe que não estava conseguindo amamentar, apresentando hipogalactia, e que tentava restabelecer a produção de leite por meio da técnica de relactação:

... porque com leite de peito o prematuro se recupera $e$ cresce mais rápido, com o leite da mãe mesmo. (Jucy)

O fato de a alta hospitalar depender, também, do sucesso da amamentação pode ser mais um fator de estresse para aquelas mães que não estavam conseguindo amamentar ou estavam vivenciando o aleitamento com dificuldades. Isso pode, de alguma maneira, exacerbar os sentimentos de insegurança e culpa por não terem sido capazes de levar uma gestação a termo e por não conseguirem dar ao filho prematuro aquilo de que ele mais precisa para crescer e se desenvolver saudável.

A análise desse tema apontou que uma das representações da amamentação para as mães de prematuros, em Cuidado Canguru, foi a relação estabelecida entre o leite materno e o crescimento e desenvolvimento saudável. A nosso ver, essa forma de representar a amamentação é, também, o resultado da interpretação, pelo senso comum, das campanhas que têm difundido a relação entre o crescimento e desenvolvimento saudável e o leite materno.

Tema 2 - Leite materno e proteção

Os núcleos de sentido que expressaram esse tema foram: defesa da criança, tem todas as vacinas, alimentação pura, é a vida da criança, não tem risco de pegar doenças/infecções/ muitas coisas/problemas.

As nutrizes que estavam amamentando, com poucas dificuldades, seus filhos prematuros, atribuíram maior número de núcleos de sentidos para esse tema.

... você tem certeza que ele não fica doente, num pega bactéria nenhuma. /.../ dar uma alimentação pura pra ele, não vou me arriscar, se for dar um outro tipo de alimentação, eu vou dar com medo de que ele venha a pegar uma infecção, de que ele venha a voltar ao hospital. (Mariana)

... porque dando de mamá, não \{_\} aparece problema nenhum e se a gente der outro leite aí aparece problema, né? (Jucy)

... no começo tem o colostro, né? Então, aquele é a principal vacina pra criança, ali é onde está todas as vacinas, defesa da criança ... aquele foi forte mesmo eu dei todo pra ele. (Elis)

A representação leite materno e proteção parece estar fortemente associada às particularidades de ter um prematuro. No caso deste estudo, nenhuma das mulheres teve outros filhos pré-termo, os riscos a que essas crianças estão expostas são percebidos por elas e expressos em suas falas. Nesse contexto, ao leite materno é atribuído o poder de recuperar o prematuro, que, na visão delas, não é um bebê saudável.

A representação da amamentação como proteção da vida da criança prematura foi identificada nos discursos de mães que estavam conseguindo amamentar seus bebês sem muitas dificuldades. Quando um sujeito pensa em um objeto, o seu universo não é uma tábua rasa, ao contrário, pensar-se-á no objeto, apoiando-se nas experiências anteriores e esquemas de pensamentos já estabelecidos $^{(15)}$. No caso, para as mães de prematuro, a sensação de perda e a percepção da morte foram vivenciadas no cotidiano, e amamentar os filhos significa, à luz de seus discursos, diminuir o risco de vida.

Pensamos que as mães que tinham dificuldades para amamentar, não correlacionaram o leite materno com 
a vida do prematuro, talvez porque, se assim o fizessem, estariam aumentando ainda mais os sentimentos de culpa e impotência frente à realidade de terem trazido ao mundo um ser ainda imaturo. Na formação de uma representação social, as informações, crenças e idéias sobre um objeto passam, num primeiro momento, por um processo de seleção e descontextualização, o qual possibilita que apenas partes das informações disponíveis sejam utilizadas, e parte delas, esquecidas, conforme a orientação dos sujeitos ${ }^{(15)}$. Esse processo pode ter sido utilizado por essas mulheres entrevistadas ao se posicionarem frente aos conteúdos teóricos que circulavam naquele contexto, onde a amamentação é enfatizada.

Tema 3 - Maternidade e amamentação

As mães que vivenciavam o aleitamento materno com poucas dificuldades atribuíram o maior número de núcleos de sentido também para esse aspecto da amamentação. Os núcleos de sentido expressados pelas nutrizes foram: uma boa mãe, uma maravilhosa mãe, sentir-se mais mãe, mãe perfeita é ter muito leite para amamentar.

Amamentar qualifica a mulher como uma boa mãe, mas, por outro lado, as mulheres que não conseguem amamentar, são vistas, por aquelas que amamentam, sem críticas; elas parecem entender os conflitos pelos quais muitas delas passam:

... porque tem mães que ... não conseguem ter leite prá dar pro filho ela se sente angustiada. (Nane)

Há, também, uma crítica às mães que não amamentam, a qual pode estar relacionada com o que estamos vivendo, nas duas últimas décadas, em relação ao aleitamento materno, ancorado em valores sociais:

Ah! Uma boa mãe. Uma maravilhosa mãe. Porque não existe ... tem mães aí que nem liga, não sabe a importância que tem pra um filho amamentar. ... eu me sinto muito bem, muito bem mesmo. Tanto que meu marido, me incentiva que só, sabe? E eu gosto muito. (Elis)

Desde o final do século XVIII, tenta-se mudar o comportamento das mulheres em relação a essa questão. São dois séculos de discursos que, em alguns momentos, avançam no sentido da valorização da amamentação e, em outros, retrocedem como o que ocorreu durante a era da industrialização do leite. A amamentação é comportamento social, mutável conforme as épocas, e sofreu transformações ao longo da história(16). Culturalmente, o ato de amamentar, seja consciente ou inconsciente, é herdado e pode ser influenciado pela família e pelo meio social em que as pessoas vivem ${ }^{(17)}$. Não amamentar os filhos era atitude socialmente aceita até o início do século XVIII. No Brasil, a partir dessa época, essa atitude foi condenada para, novamente, já no século XX, em especial a partir do final da década de 40 , ser novamente aceita ${ }^{(18)}$ e, de certa maneira, incentivada pelos representantes do discurso científico - os profissionais da área de saúde.

A representação mãe que não amamenta é negligente foi enfatizada no discurso de uma mãe que fez uma condenação explícita às mães que não estavam amamentando os prematuros na unidade em que estava internada; esses bebês ficam temporariamente afastados de suas mães que, na maioria, estão internadas em outro andar do hospital.

As meninas (auxiliares) dão comida, mas eles continuam chorando a noite inteira ... elas dizem: Mariana, é o carinho materno que eles tão necessitando. Então, isso dói, né? Se não tem capacidade, se não tem amor próprio, então não tenha filho. /.../ toda mãe deveria amamentar seu filho, sem exceção. (Mariana)

Para as mães que amamentavam seus filhos sem conflitos aparentes, toda boa mãe tem o dever ou a obrigação de amamentar, correlacionam amor materno diretamente à prática do aleitamento materno. Ao que indica o seu discurso, as mães que não amamentam, são, no mínimo, indignas da maternidade.

No contexto do aqui-agora, as mães atribuíram significados à amamentação, os quais podem ter sido influenciados pelo contexto, onde o que é esperado delas é o sucesso na amamentação.

Tema 4 - Amamentação e amor materno

Ao atribuírem significado a esse tema, as mães o fizeram por meio dos seguintes núcleos de sentido: carinho da mãe, amor da mãe, contato direto, sente o calor da mãe, contato no olhar, eu, ela e o leite é uma ligação só. Os recortes dos discursos expressam alguns desses núcleos:

Eu acredito que amamentar também é uma forma de carinho, de dar carinho pra eles. O meu pequinininho, que parece um passarinho, ele começa a chorar, se eu botar no peito, rapidinho ele se cala. (Mariana)

... pra que ela sinta que eu sou mãe dela, é o conjunto completo. O meu leite é uma coisa de mim, então se ela nasceu de mim eu acho que eu, ela e o leite é uma ligação só. (Verônica)

$\mathrm{Na}$ fala das mães, ao representarem 
amamentação como demonstração de amor, elas o fazem em contrapondo com a alimentação artificial. Dentro dessa óptica, a demonstração de amor da mãe para com o filho e a relação de apego só são possíveis por meio da amamentação materna; a mamadeira parece representar algo que artificializa a relação afetiva. Isso decorre, segundo elas, do contato direto proporcionado pela amamentação, o que não seria possível por meio da alimentação artificial.

Porém, nem todas as mulheres vivenciam a amamentação como uma prática que lhes é gratificante e, quando a amamentação é percebida por elas como um fardo, essa proximidade que favoreceria a relação de apego pode ser comprometida. No entanto, isso não significa ausência de amor materno.

$O$ ato de amamentar ou não um filho não pode ser tomado como demonstração de amor materno ${ }^{(19)}$. Acreditamos que o discurso técnico que representamos, em especial nós, profissionais da enfermagem, tem reforçado, mesmo que sutilmente, a amamentação como demonstração de amor materno. Essa postura colocanos, muitas vezes, diante de situações delicadas frente às mães de prematuros que, por dificuldades que ultrapassam a sua vontade, ou por decisão pessoal, não estão amamentando.

As representações construídas sobre o aleitamento materno e a realidade que se apresentava para algumas mães com dificuldade para amamentar, provavelmente as faziam sofrer ao encarar a contradição de acreditar que a amamentação era o melhor que poderiam oferecer aos filhos prematuros e, em contrapartida constatar que, apesar de seus esforços, fracassavam como nutriz. Esse último aspecto está representado na fala de Verônica:

... mãe perfeita é aquela que tem leite pra amamentar. (Verônica)

Pelo que pudemos perceber, essa mãe manteve uma coerência nas suas representações sobre o objeto a amamentação do filho pré-termo -, mesmo que essas a fizessem sofrer. Provavelmente, as respostas que são esperadas dela pelo seu grupo de pertença social e as interações que estabeleceu no contexto, corroboraram para que, mesmo amamentando com dificuldades, representasse $o$ ato de amamentar fundamental na relação de apego.

Diferentemente, Jucy e Elma, que apresentavam dificuldades para amamentar, não expressaram, por meio de suas falas e nem mesmo conseguimos captar pela observação de campo, a correlação entre a amamentação e a relação de vínculo. Provavelmente porque, para elas, amamentar era uma prática difícil de se realizar.

... a amamentação é melhor para o bebê. (Elma)

Percebemos, por meio da observação de campo, que essas mulheres não se sentiam seguras como nutrizes, e a incapacidade emocional de amamentar, embora no discurso técnico apareça como importante no mecanismo de ejeção do leite, na prática não chega a ser considerada.

As representações sociais sobre o aleitamento materno estão sendo construídas coletivamente, ou seja, elas não são a simples reprodução do discurso técnico científico. Embora o contexto social em que são elaboradas seja relevante para o processo de construção e compreensão dos significados, as mães, ao representarem a amamentação nos diferentes aspectos, impõem, também, a sua subjetividade na maneira como interpretam e reapresentam esses conteúdos. Assim, ao representarem um aspecto do aleitamento materno, as nutrizes deste estudo não o fizeram deslocado do seu contexto social (temporal) e de sua subjetividade.

Tema 5 - A prática de amamentar um prematuro

A prática da amamentação não é representada e nem percebida da mesma forma por todas as mulheres. A amamentação pode ser sentida por algumas nutrizes como uma prática que proporciona prazer e gratificação, porém outras poderão senti-la como uma prática conflituosa que evoca sensações desconfortáveis como medo, insegurança, dor, entre outros sentimentos. Não raro, a mesma nutriz pode perceber a amamentação como sendo agradável em alguns momentos e desconfortável em outros.

Esses aspectos do ato de amamentar têm sido discutidos, pois as representações socioculturais do aleitamento estão atreladas também ao significado que a sociedade atribui à maternidade ${ }^{(14)}$.

No nosso estudo, as mães que estavam amamentando com poucas dificuldades percebiam $o$ ato de amamentar como uma prática gratificante, definida nos seguintes núcleos de sentido, emergentes em seus discursos: uma coisa maravilhosa, experiência tão gostosa, sensação agradável. Todavia, a maioria das entrevistadas, em seus discursos, no início da amamentação materna, 
deparava-se com sentimentos de medo e insegurança decorrentes das particularidades de ter um filho pré-termo, o qual permaneceu por determinado período em cuidado intensivo.

Quase todas as nutrizes, mães de crianças prétermo, passam por um período estressante do qual emergem os conflitos e as contradições entre o discurso técnico e a prática de amamentar essas crianças. A dúvida e o conflito quanto à capacidade de manter a lactação por meio da ordenha, confrontados com as orientações recebidas, que enfatizam a sucção direta no peito, o medo de o bebê não conseguir pegar o peito, os efeitos do ingurgitamento mamário e a dor que acompanha a ordenha manual ou mecânica fazem parte do cotidiano dessas mães enquanto seus filhos não sugam, diretamente, o seio materno. Nessa fase, mesmo aquelas mulheres que referiram a prática como gratificante, às vezes de forma sutil, expressaram as contradições e conflitos como identificamos nas falas abaixo:

... quando \{_\}. o seu nenê \{_\} não tá conseguindo se alimentar, você fica assim... ansiosa. (Nane)

É assim um pouco triste, né? Porque sabe que em vez de ele tá mamando direto, você tem que dar pra passar por uma seringa e outro aparelho pra poder chegar até ele, né? Não é uma sensação gostosa não. $\left.E_{\left\{\_\right.}\right\}$uma coisa triste, você não sente bem. (Mariana)

Foi diferente do meu primeiro, ele nasceu e sugou. Foi difícil, foi muito difícil mesmo, porque a gente sabe que vai tirar o leite, não sabe se realmente vai chegar a dar o peito, né, a gente fica naquela dúvida, meu Deus! Será que realmente ele vai sugar o peito? Será que ele vai se adaptar ao peito? /.../. então eu fiquei com aquela dúvida, aquele receio, de repente o leite não vim mais /.../ eu falei pra uma enfermeira ... ela me disse que eu tinha que tá tirando, ...pra poder o leite ter produção ... Eu fiquei tirando com desmamador, dói muito, é muito sofrimento, mais tem que ser assim, né. (Elis)

Passada a fase de transição do aleitamento por sonda gástrica, para a sucção direta no peito, as mães referiram que sentiam a prática da amamentação como algo que as gratificava, expressando: experiência maravilhosa, gostosa, sensação agradável.

Das seis entrevistadas, somente duas sentiam a prática de amamentar um prematuro como gratificante e, mesmo assim, na fase de transição, essas mesmas nutrizes vivenciaram sentimentos contraditórios de medo, ansiedade e insegurança. Pelos discursos e pelo que captamos por meio da observação de campo, esses sentimentos foram substituídos por outros, menos conflitantes, na fase em que conseguiram amamentar seus bebês.

\section{DISCUSSÃO}

Algumas das representações dessas mulheres, que, para nós, podem ter sido moldadas não só no período de socialização (tempo vivido), mas também na relação que estabelecem na unidade em que estão internadas, podem ser geradoras de conflitos. A prática que esperamos delas é o sucesso na amamentação, por sua vez, as nutrizes estão imersas em um contexto institucional onde não só o discurso técnico reforça o poder do leite materno na recuperação do pré-termo, mas também constatam o poder desse discurso ao conviverem com "nutrizes competentes", cujos filhos não demoram a alcançar o tão almejado "peito livre", critério importante para o recebimento da alta hospitalar. As nutrizes sabem que o esperado delas, enquanto mães competentes, é o sucesso na amamentação, entretanto sentem que dar o peito a uma criança prematura é uma tarefa complexa, que dificilmente é discutida com elas sob essa óptica.

Num contexto institucional, de certa forma pouco flexível para o aleitamento artificial, mães pareciam insatisfeitas e nervosas com o fato de terem que amamentar, embora não tivessem verbalizado de maneira objetiva sua insatisfação. Ao contrário, no discurso e mesmo nas observações, buscavam encontrar justificativas externas a sua vontade para se justificarem. O que apreendemos da análise desse tema é que a maioria das mães representou, naquele momento, o aleitamento materno do filho pré-termo como uma prática difícil e desgastante.

As representações sociais exteriorizadas sinalizam para a apreensão de aspectos dos conteúdos científicos acerca do aleitamento materno e que, de certa forma, representam a racionalidade científica, reinterpretadas à luz do conhecimento do senso comum.

Os significados atribuídos ao aleitamento materno trazem conteúdos reelaborados das teorias sobre alimentação infantil, que circulam no cotidiano de vida dessas mulheres, por meio do contato com os serviços, práticas assistenciais e com conteúdos simbólicos veiculados em vários canais de informações. Embora essas representações denotem que houve assimilação do discurso técnico sobre amamentação materna, isso, por si só, não garante o sucesso da prática do aleitamento em situação de prematuridade.

Para nós, essa contradição é fruto, também, das especificidades de amamentar um pré-termo, pois a 
maioria das mães passa por etapas que efetivamente interferem, em menor ou maior grau, no processo de lactação, na estrutura emocional e familiar.

\section{CONSIDERAÇÕES FINAIS}

O Cuidado Canguru inclui práticas que podem contemplar a afetividade, a integralidade do cuidado e o incentivo ao aleitamento materno. Ao que parece, na unidade investigada, esse último aspecto vem sendo efetivado, pois parcela significativa dos prematuros aí atendidos recebe alta hospitalar em aleitamento materno. Porém acreditamos que a inclusão de novos instrumentos no processo de trabalho dessa metodologia assistencial pode auxiliar no alcance dos objetivos desejados, diminuindo o sofrimento e os conflitos das nutrizes.

Para prestarmos os cuidados de enfermagem a essa clientela, na perspectiva da integralidade da assistência, é preciso, antes de tudo, termos sensibilidade para perceber que essas mulheres não são abstratas, mas estão inseridas em contextos sociais concretos e que trazem, de forma explícita ou sutil, as dores do vivido.

Assim sendo, é necessário que os agentes sociais tenham a dimensão desse novo recorte intelectual para instrumentalizar a prática fundamentada nas ciências humanas e sociais. Nessa perspectiva, o objeto de ação amplia-se para além do corpo anátomo-fisiológico (prematuro-peito), contemplando as questões sociais e pessoais da vivência da mãe.

Acreditamos que essas nutrizes necessitam de

\section{REFERÊNCIAS BIBLIOGRÁFICAS}

1. Scochi CGS. A humanização da assistência hospitalar ao bebê prematuro: bases teóricas para o cuidado de enfermagem. [tese]. Ribeirão Preto (SP): Escola de Enfermagem de Ribeirão Preto/USP; 2000.

2. Whitelaw A, Sleath K. Myth of the marsupial mother: home care of very low birth weight babies in Bogota, Colombia. Lancet 1985; 1(8439):1206-8.

3. Portaria $n^{\circ} 693$ de 5 de julho de 2000. [on line]. [acessado em 12 de nov 2001]. Dispõe sobre norma de orientação para implantação do método canguru. Brasília (DF): Ministério da Saúde; 2000. Disponível em: URL: http:// www.saúde.gov.com.br

4. Anderson GC. Current knowledge about skin-to-skin (kangaroo) care for preterm infants. Breastfeeding Rev 1993 Nov; 8:364-72.

5. Legoult M, Goulet C. Comparison of kangaroo and traditional methods of removing preterm infants from incubators. JOGNN 1995; 24(6):501-6. um sistema especial de apoio, pois, após um tempo de internação relativamente prolongado, os cuidados e as orientações individuais ou coletivas não devem se limitar aos aspectos técnicos, vantagens biológicas e nutricionais do aleitamento materno. É preciso implantar outras abordagens que contemplem as particularidades de cada sujeito.

Portanto, precisamos olhar para cada mãe, não como uma nutriz fracassada, mas, sim, como uma mulher que está envolvida numa trama de sentimentos, emoções e contradições decorrentes da situação de ter um filho prematuro e das dificuldades de ter que amamentá-lo.

Adotar novos instrumentos significa rever alguns aspectos de nossa prática diária. É preciso que tenhamos coragem de admitir e discutir que a amamentação materna pode ser prazerosa e menos complicada para algumas mulheres; para outras, difícil e desgastante. Incentivar o aleitamento materno, especialmente para mães de prematuros que vivenciam a iminência do fracasso, requer que tenhamos posições e abordagens que considerem os aspectos multifatoriais da amamentação materna.

Acreditamos que os resultados encontrados no estudo fornecem subsídios para a reflexão da prática profissional em relação ao aleitamento materno, elucidando particularidades do processo vivenciado por algumas mulheres. Por outro lado, sabemos que o recorte temporal analisado é parte de um continum da atenção à saúde desse grupo populacional que envolve intervenção na área de saúde da mulher, pré-natal, assistência hospitalar ao parto e recém-nascido, e seguimento na rede básica de serviços de saúde e comunidade.

6. Charpak N, Calume ZF, Hamel A. O método mãe canguru: pais e familiares dos bebês prematuros podem substituir as incubadoras. Rio de Janeiro: McGraw Hill; 1999.

7. Barros MD, Yamashiro E, Barreto O, Sampaio MMSC. Características do leite de mães de recém-nascidos de baixo peso. Pediatria 1984; 6(2):53-7.

8. Briansó BA, Trejos AM, Mora AB, Arauz AG. Evaluacion de la tolerancia y velocidad del crecimiento del recien nacido de pretermino con diferentes tipos de leche. Rev Costarric $\mathrm{Ci}$ Med 1987; 8(4):217-27.

9. Cattaneo A, Davanzo R, Uxa F, Tamburlini G. Recommendation for the implementation of kangaroo mother care for low birthweight infants. Acta Paediatr 1998; 87(4):4405.

10. Haguette TMF. Metodologias qualitativas na sociologia. Petrópolis (RJ): Vozes; 1992.

11. Jodelet $D$. Représentations sociales: un domaine en expansion. In: Jodelet $D$, organizadora. Les representations sociales. Paris: Presses Universitaires de France; 1984. p. 31-61. 
12. Spink MJ. Desvendando as teorias implícitas: uma metodologia de análise das representações sociais. In: Guarescui P, Jovchelovitch S, organizadoras. Textos em representações sociais. $2^{\underline{a}}$ ed. Petrópolis (RJ): Vozes; 1995. p. 117-45.

13. Bardin L. Análise de conteúdo. Lisboa: Edições 70; 1977. 14. Silva IA. Amamentar: uma questão de assumir riscos ou garantir benefícios. [tese]. São Paulo (SP): Escola de Enfermagem/USP; 1994.

15. Vala J. Representações sociais para uma psicologia social do pensamento social. In: Vala J, Monteiro MB. Psicologia social. Lisboa: Fund. Calustre/Gulbenkein; 1993. 16. Silva AAM. Amamentação fardo ou desejo? Estudo histórico-social dos saberes e práticas sobre aleitamento materno na sociedade brasileira. [dissertação]. Ribeirão Preto (SP): Faculdade de Medicina de Ribeirão Preto/USP; 1990. 17. Ichisato SMT, Shimo AKK. Revisitando o desmame precoce através de recortes da história. Rev Latino-am Enfermagem 2002 julho; 10(4):578-85.

18. Badinter E. Um amor conquistado: o mito do amor materno. 5 $5^{\text {a }}$ ed. Rio de Janeiro (RJ): Nova Fronteira; 1985.

19. Klaus HM, Kennel HJ. Pais e bebês: a formação do apego. Porto Alegre (RS): Artes Médicas; 1993. 